\title{
DOCUMENTATION OF OLD TURKIC RUNIC INSCRIPTIONS OF THE ALTAI MOUNTAINS USING PHOTOGRAMMETRIC TECHNOLOGY
}

\author{
M. V. Vavulin \\ Laboratory for Social and Anthropological Research, Tomsk State University, Tomsk, Russia - 0002004@inbox.ru
}

Commission II

KEY WORDS: 3D documentation, Altai Mountains, Digital Photogrammetry, Runic inscriptions, Turks

\begin{abstract}
:
Old Turkic runic inscriptions of the Altai Mountains (8th-9th centuries AD) were digitized in the course of this project to be preserved in the current state on the Web and deciphered by linguistic experts. The ways the inscriptions were made as well as their location in hardly accessible areas required finding an inexpensive solution that would provide detailed 3D documentation of rock faces, while at the same time mobility and autonomy. Digital photogrammetry came as a quite affordable and optimal choice for getting high-quality outcomes using inexpensive software and further data processing using free software.
\end{abstract}

\section{INTRODUCTION}

So far, Old Turkic runic inscriptions of the Altai Mountains (8th-9th centuries AD) have been studied less than the welldocumented epitaphs on the stone steles in Mongolia, Khakassia and Tuva. It was only in the 2000 s that ancient runic manuscripts of Altai began to be methodically catalogued (Tybykova et al., 2012). It is in the Altai Mountains that more and more ancient runic inscriptions have been discovered over the last decades. About 90 inscriptions are known today, most of them still undeciphered and disputed by turkologists from all over the world. It is vital to document and preserve these priceless runic monuments for science, as many have already been lost irretrievably due to blasting operations during road construction, earthquake rockfalls, and acts of vandalism. Apart from specific linguistic issues, deciphering the Altai inscriptions is hampered significantly by the way the inscriptions were made. Freshly-cut lines used to be in contrast with the rock face but grew less and less discernible with time. Today, the naked eye can barely see them from a specific angle under special light. In some cases, runes are also difficult to read because of more recent petroglyphs and modern-day graffiti. Besides, natural stone defects and fractures can be easily mistaken for manmade lines.

The ways researchers reproduce the same inscriptions differ so much that highly varied readings become possible. Available physical contact methods, traditionally used to document petroglyphs, are not suitable for providing a reliable documentation of runic inscriptions. For instance, the method of copying petroglyphs on mica-coated paper, which has been widely spread in Russia, has some serious limitations even for petroglyphs. Such copies can be completely useless in case of shallow runic inscriptions.

\section{SUBJECT OF RESEARCH AND CHOICE OF TECHNOLOGY}

\subsection{Subject of research}

The runic inscriptions in question are located in Ongudaysky and Kosh-Agachsky Districts of the Altai Republic, Russia (Fig.1). The inscriptions were made on mostly vertical rock

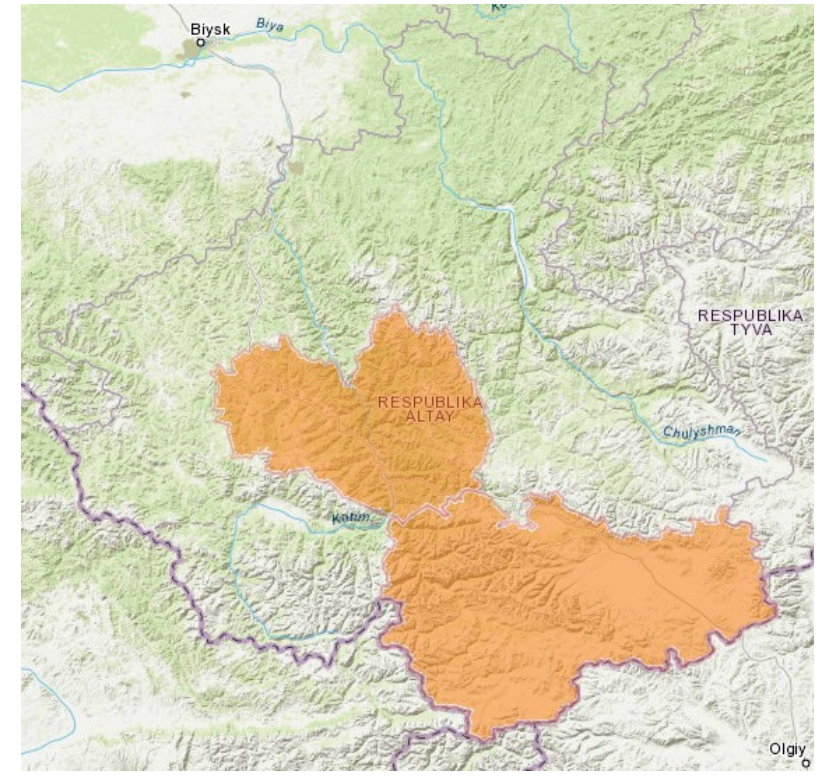

Figure 1. Ongudaysky and Kosh-Agachsky Districts of the Altai Republic, Russia

faces of 0.02 to 1 sq. $\mathrm{m}$. They differ in length and can comprise from a few runes to a few dozens. The carvings are thin (cutting width $0.1-1 \mathrm{~mm}$, cutting depth often less than $0.1 \mathrm{~mm}$ ) and normally small, about $1-3 \mathrm{~cm}$ long, which makes them very difficult to copy and read. The rune cutting techniques described above require not only high-resolution macro photography but also rock relief capturing in order to provide reliable documentation.

\subsection{Choice of technology}

Modern commercial market offers 3D scanners of numerous brands, capable of scanning tiny details on the surface of objects. Various technologies are used: structured light, laser scanning, computed tomography, etc. Such scanners are largely expensive and either stationary or dependent on robot manipulators, which cannot be applied in hardly accessible areas. 
Meanwhile, very few portable 3D scanners have a resolution over $0.1 \mathrm{~mm}$, and they also cost a lot.

Among less expensive solutions (under EUR20,000), only structured-light models can boast specifications sufficient to document runic inscriptions. However, they depend heavily on ambient light and require an external power supply. Such equipment cannot be used to document runic inscriptions in hardly accessible mountain areas.

Therefore, it was decided to use the photogrammetric technology, which allows survey mobility and autonomy.

\section{SURVEYING}

\subsection{Estimating maximum allowable resolution}

The highest-resolution photo camera and the highest-focallength macro photo lens were selected from the available laboratory equipment to provide maximum detail enhancement possible. Data was collected using a Nikon D800 with an effective image resolution of $7360 \times 4912$ pixels (36.15 MP) and a $35.9 \times 24 \mathrm{~mm}$ sensor. Shooting was performed using a Sigma $105 \mathrm{~mm}$ f/2.8 EX DG OS HSM Macro Lens with the closest focusing distance of $31.2 \mathrm{~cm}$.

The following formula was used to estimate maximum Ground Sample Distance attainable for this equipment combination:

$$
G S D=\frac{D \times L_{s}}{f \times L_{p x}}
$$

where: $\quad G S D=$ Ground Sample Distance

$D=$ distance to object

$L s=$ sensor size

$L p x=$ image size (in pixels)

$f=$ focal length

Estimated ground sampling distance is slightly less than $0.015 \mathrm{~mm}$ at the minimum focus distance of $31.2-32.2 \mathrm{~cm}$. Such GSD allows for 3D models with resolutions down to $0.015 \mathrm{~mm}$, which should be enough to document details as tiny as $0.05 \mathrm{~mm}$ on the surface, if required (Vavulin et al., 2014).

\subsection{Surveying}

The camera was mounted perpendicular to the digitized plane at a distance of $32-70 \mathrm{~cm}$ from it, depending on tripod mounting configuration. The survey was conducted with the film speed fixed at 100 and the lens set at $\mathrm{f} / 20$; shutter speed was adjusted to ambient light until correct exposure was achieved. During the survey, it was crucial to avoid deviation of the optical axis of the lens from the plane perpendicular to the digitized one, since the small focusing distance resulted in fairly shallow depth of field even with high f-numbers. Images were recorded in the JPEG format. Depending on the time of the day and weather conditions, shooting was performed either under evenly dispersed natural light or in artificial shadow covering the whole surface. No additional sources of light were used. Since rock faces with runic inscriptions represent planes of poorly defined geometry, the same shooting procedure as with aerial photogrammetry was followed (Agisoft PhotoScan User Manual, 2017). The camera was moving vertically, parallel to the digitized plane, with a $70 \%$ image overlap; a side overlap of
$60 \%$ was provided using a parallel shift between the flights of images.

Scaling was performed by manually measuring the distance between two pre-marked points.

\subsection{Data processing}

Agisoft Photoscan Pro software was used to process the data. Processing included several stages.

- Photo alignment.

- Building a model using sparse point cloud.

- Model scaling and adjustment in the local coordinate system; bounding box alignment.

- Dividing the common bounding box into chunks using a relevant script from:

http://wiki.agisoft.com/wiki/Split_in_chunks.py

Total surface was divided in such a way that each individual chunk would not contain more than $30 \mathrm{mln}$ points after a dense point cloud was generated.

Batch processing was used at all the subsequent stages.

- Building Ultra-high quality dense point clouds for every chunk created.

- Exporting the resulting dense point clouds in the PLY file format.

- Merging the dense clouds into one chunk.

merged chunk.

- Generating Digital Elevation Model (DEM) for the

- Generating orthophoto for the merged chunk.

file.

- Exporting DEM as a single GeoTIFF Elevation Data split into 1,024-pixel square blocks.

- Exporting orthophoto in the GeoTIFF file format.

In case the quality of the resulting orthophoto was not satisfactory (the image was partly unfocused, etc.), the necessary corrections were performed manually and the orthophoto was re-exported.

In addition, simplified textured models (of up to $1 \mathrm{mln}$ polygons) were created for publishing on the Web.

\section{DATA ANALYSIS}

\subsection{D and 2.5D data analysis.}

QGIS Desktop software was used to analyze orthophoto and DEM. Several clusters of lines with differing characteristics can be found on the surface of an object. Such lines can differ in style, length, width, depth or chromaticity. The following layers were created to analyze all these features:

- One-piece DEM to display the overall relief of the whole surface and build profiles (Fig.2, b);

- DEM split into small squares to display the surface relief of small sections in details (Fig.2, c);

- DEM as shaded relief images (Hillshade render type) to display the surface relief in a more human-readable format (Fig. 2, d);

- Orthophoto (Fig.2, a);

- DEM as shaded relief images in the "Soft light" blending mode to be used over the orthophoto and thus ensure simultaneous perception of texture and relief (Fig.2, e).

The Profile Tool plugin was used to create profiles. 


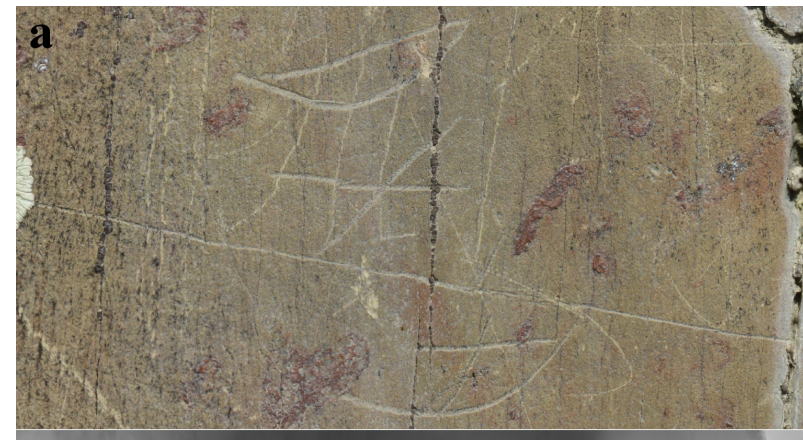

b
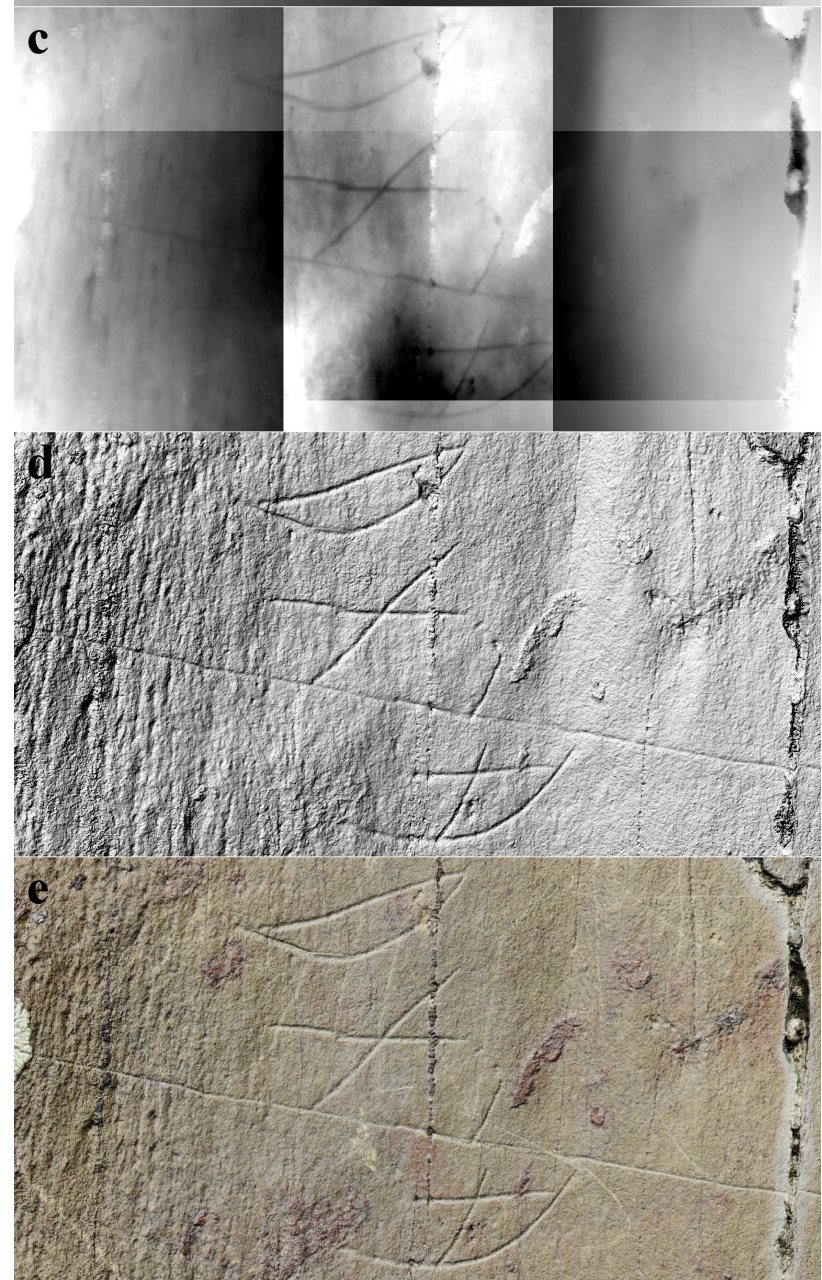

0

$5 \mathrm{~cm}$

Figure 2: Layers to analyze features

a - orthophoto, b - Digital Elevation Model (DEM), c - splitted DEM, d - DEM with hillshade render type, e - DEM with hillshade render type in the soft light blending mode over the orthophoto

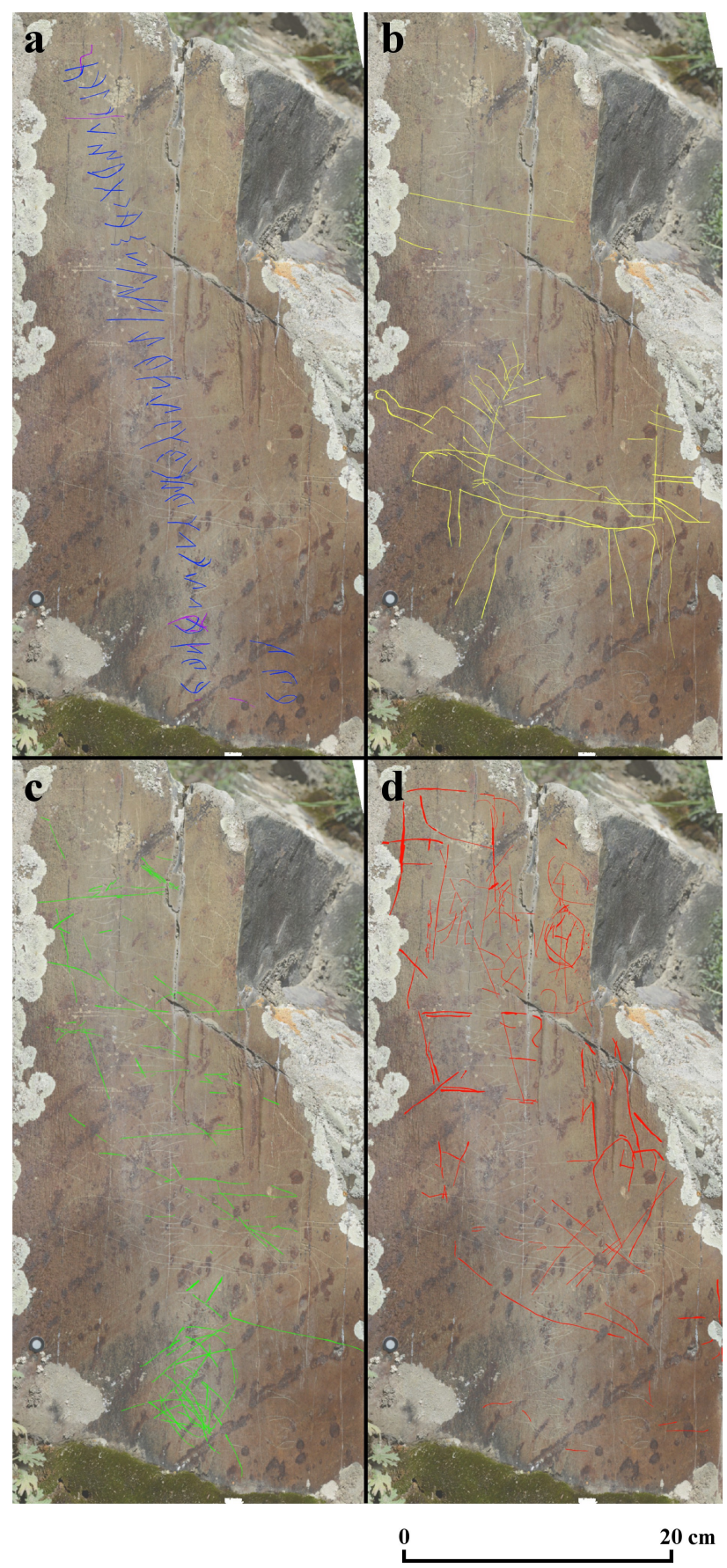

Figure 3. Types of lines a - types $1-2$, b - type $3, \mathrm{c}$ - type 4, d - type 5

Let us analyze the inscription "Bichictu-Boom III" (A-16) as an example (http://www.altay.uni-frankfurt.de). Several types of lines were discovered on the surface.

In most cases, the runic lines can be easily identified; they are no more than $5 \mathrm{~cm}$ long, on average $0.6 \mathrm{~mm}$ wide and 0.06 $0.12 \mathrm{~mm}$ deep. They are largely straight and distinguishably lighter than the shade of the background rock face (Fig.3, a).

The second type of lines shares most of its characteristics with the first one. These lines have the same length, width and shade. However, they are much shallower, about only $0.03-0.06 \mathrm{~mm}$ 
deep. It may be that all or some of them also make part of the runic inscription (Fig.3, a).

Lines of the third type have the same width, depth and shade as the first one, yet they are considerably longer, sometimes reaching $14 \mathrm{~cm}$ (Fig.3, b).

The fourth type differs sharply from the previous three. The arcshaped lines are $3-12 \mathrm{~cm}$ long, $0.5-1 \mathrm{~mm}$ wide and $0.01-$ $0.05 \mathrm{~mm}$ deep. Their shade largely melts into the background rock face (Fig.3, c).

Finally, lines of the fifth type rather represent scratches than carvings. They are easily distinguishable due to their lighter shades but have no depth at all. Their sizes and forms vary (Fig.3, d).

Lines of each type were rasterized individually in relevant vector layers. The resulting image contributes a lot to the rasterized data from previous surveys (Fig. 4).

a

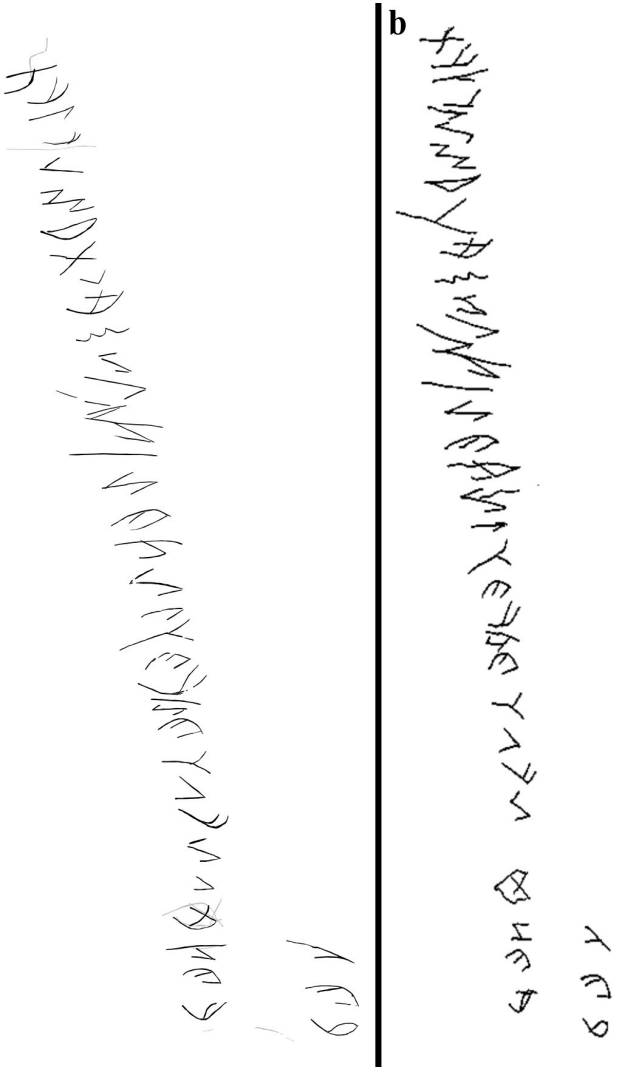

Figure 4. Drawings of runes a - new result, b - previous survey (image from http://www.altay.uni-frankfurt.de/english/a16/bich3_x.png)

\subsection{D data analysis.}

3D data analysis can be performed by uploading point clouds to 3D data viewing software, such as Meshlab, CloudCompare, etc. First of all, this will allow analyzing the microrelief and the texture simultaneously under any angle, examining the characteristics of lines and the way they cross one another, etc. 3D object comparison tools can also be applied to visualize the tiniest details. This can be done using either a point cloud or a generated polygon model, depending on software functionality.
In our case, the resulting model was exported to Geomagic Wrap, a 3D editing tool, where the point cloud was converted to an untextured polygon model (only relief matters in this case). Next, the editor created a model, which was then smoothed, so that tiny details and sharp edges on the surface got blurred. Next, the original model was checked for discrepancies with the smoothed one, so that all fine details and sharp edges became clearly seen (Fig. 5).

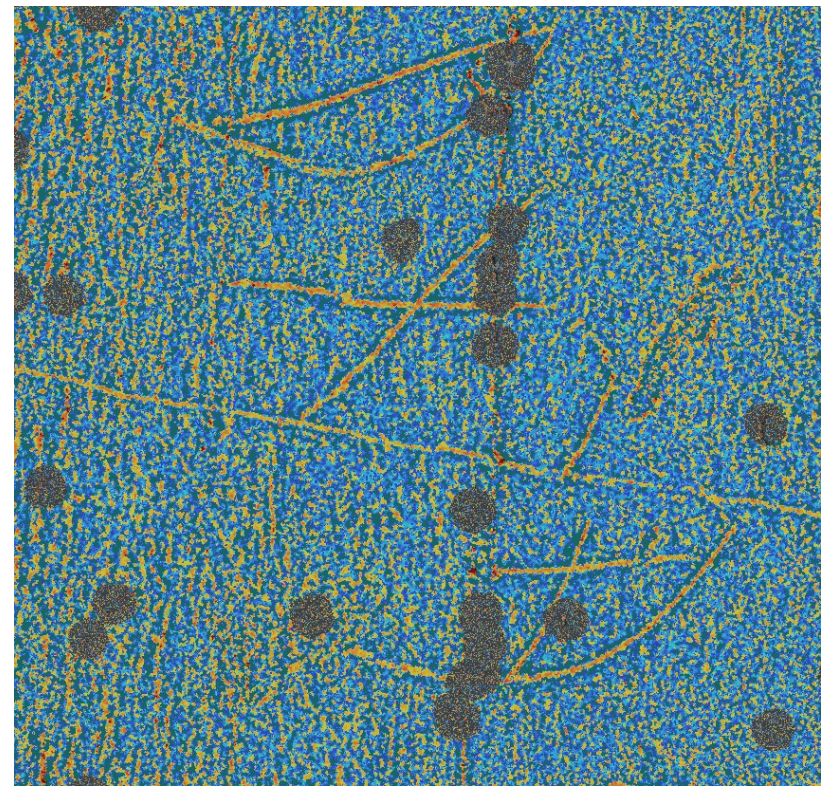

Figure 5. Deviations between two models

\section{CHALLENGES}

Some issues were encountered during the documentation of runic inscriptions. First, the tripod could not always be mounted at a proper distance from the object. As a result, some models did not have sufficient resolution to display the surface relief. Second, the tripod could not always be mounted properly relative to the digitized plane. Because shooting was performed at angles, the depth of field was sometimes not enough to clearly display the whole plane, resulting in errors not only in geometry construction but also during orthophoto generation (defects in relevant areas). Third, it was not always possible to ensure proper image overlap, which resulted in small holes in some of the models. To handle these three issues, a tripodmounted slider with markings is going to be used in future field surveys to allow operating the camera easily in the horizontal plane, too. Finally, some rock faces are so hardly accessible that they cannot be shot using a tripod without installing special platforms.

Challenges with large data volumes were encountered at the stage of data processing. Originally, textured polygon 3D model were going to be used as the key result of digitization and the basic source for analysis. Although the graphics workstation managed all calculations successfully, it was hardly possible to view the resulting models (of 200-300 mln polygons) at regular workstations, let alone working with them. That is why, first, it was decided to stop using polygon models and use dense point clouds as the key result of digitization instead, which increased performance of 3D data viewers dramatically. Dense point clouds are also the building material for polygon models, so 
they can be used to generate such models and analyze them, if necessary. Since dense point clouds were generated with maximum possible resolution during data processing, point colors comprise all the available information on textures. Second, the resulting files were still too big to be easily worked with at workstations $(80-150 \mathrm{mln}$ points) even if point clouds were used. Therefore, total surface of a single object was divided into pieces of up to $30 \mathrm{mln}$ points each. The PLY file format was chosen to export point clouds, as it shows good data compression performance and most of available $3 \mathrm{D}$ data viewers supports it.

\section{CONCLUSION}

Thirty Altai runic inscriptions of the Old Turkic era were eventually documented in 2017. Photogrammetry, in this case, proved to be not only the cheapest solution but also the optimal choice. The resulting data represents the first attempt of runic monument digital documentation that will help solve the ageold disputes over specific runes in rock inscriptions. It will also allow preserving ancient manuscripts in their current state at least in digital form. As soon as they are posted online, they will become accessible to any turkologist around the world, thus giving a new impetus to progress in deciphering. Besides, the project will bring into sharp focus the long-term benefits of using 3D recording for the preservation and popularization of archaeological and epigraphic heritage in Russia, where such projects are extremely rare today (Plets et al., 2012; Zaytseva, 2014; Plisson and Zotkina, 2015; Pushkarev et al., 2016; Zaitceva et al., 2016 ).

\section{ACKNOWLEDGEMENTS}

This work was conducted as a government task of the Ministry of Education and Science of the Russian Federation, Project Number 33.8576.2017/9.10

\section{REFERENCES}

Agisoft PhotoScan User Manual: Professional Edition, Version 1.3, 2017. p.8 http://www.agisoft.com/pdf/photoscanpro_1_3_en.pdf

Plets, G., Gheyle, W., Verhoeven, G., De Reu, J., Burgeois, J. Verhegge, J. and Stichelbaut, B., 2012. Three-dimensional recording of archaeological remains in the Altai Mountains. Antiquity, 86, pp. 884-897

Plisson, H. and Zotkina, L.V., 2015. From 2D to 3D at macro and microscopic scale in rock art studies. Digital Applications in Archaeology and Cultural Heritage, 2 (2-3), pp. 102-119.

Pushkarev, A. A., Zaytceva, O. V., Vavulin, M. V. and Skorobogatova, A. Y., 2016. 3D recording of a 19-century $\mathrm{Ob}$ River Ship. The International Archives of the Photogrammetry, Remote Sensing and Spatial Information Sciences, Prague, Czech Republic, Volume XLI-B5, pp.377-381

Tybykova, L. N., Nevskaja, I. A. and Erdal, M., 2012. Katalog drevnetjurkskix runičeskix pamjatnikov Gornogo Altaja. GornoAltajsk.
Vavulin, M.V., Zaytseva, O.V. and Pushkarev, A.A., 2014. 3D scanning techniques and practices used for different types of archaeological artifacts. Siberian Historical Research, 4, pp.2137.

Zaitceva, O. V., Vavulin, M.V., Pushkarev, A.A. and Vodyasov, E.V., 2016. Photogrammetry: From Field Recording to Museum Presentation (Timiryazevo burial site, Western Siberia). Mediterranean Archaeology and Archaeometry, 16(5), pp. 97-103.

Zaytseva, O.V., 2014. 3D revolution in archaeological recording in Russian perspective. Siberian Historical Research, 4, pp.1020 . 